Thermodynamic Modeling of Hydrogen

Fluoride Production Relevant to Actinide

Residue Treatment

Mike H. West

Keith M. Axler 


\section{DISCLAIMER}

This report was prepared as an account of work sponsored by an agency of the United States Government. Neither the United States Government nor any agency thereof, nor any of their employees, make any warranty, express or implied, or assumes any legal liability or responsibility for the accuracy, completeness, or usefulness of any information, apparatus, product, or process disclosed, or represents that its use would not infringe privately owned rights. Reference herein to any specific commercial product, process, or service by trade name, trademark, manufacturer, or otherwise does not necessarily constitute or imply its endorsement, recommendation, or favoring by the United States Government or any agency thereof. The views and opinions of authors expressed herein do not necessarily state or reflect those of the United States Government or any agency thereof. 


\section{DISCLAIMER}

Portions of this document may be illegible in electronic image products. Images are produced from the best available original document. 


\section{Contents}

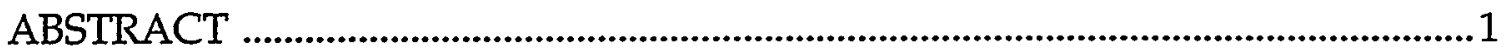

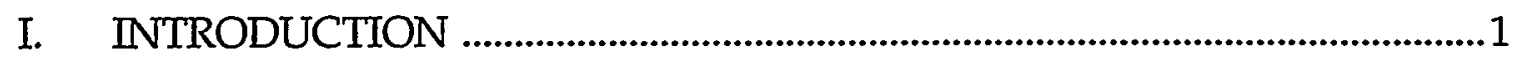

II. PRELIMINARY RESULTS OF COMPUTER MODELING ................................

A. Computer Modeling of HF Generation via the $\mathrm{CaF}_{2}-\mathrm{H}_{2} \mathrm{SO}_{4}$ Reaction in $\mathrm{Air}$.......................................................................

B. Computer Modeling of HF Generation via the $\mathrm{MgF}_{2}-\mathrm{H}_{2} \mathrm{SO}_{4}$ Reaction in Air ....................................................................

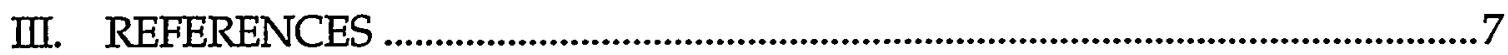




\title{
THERMODYNAMIC MODELING OF HYDROGEN FLUORIDE PRODUCTION RELEVANT TO ACTINIDE RESIDUE TREATMENT
}

by

\author{
Mike H. West and Keith M. Axler
}

\begin{abstract}
This report addresses issues specific to the generation of hydrogen fluoride via reaction of calcium fluoride with sulfuric acid. This process has been established on a commercial scale and is under consideration for treatment of calcium fluoride residues from uranium processing. Magnesium fluoride slags are also available as a product of uranium processing. The technique of using sulfuric acid for the production of hydrogen fluoride from magnesium fluoride is also under consideration as a residue processing scheme. In the current study, thermodynamic modeling was used to investigate these chemical processing systems. The results presented herein reveal information relevant to the selection of processing temperatures and conditions. Details include predicted effects in system composition based on operating temperatures for both the calcium fluoride and the magnesium fluoride systems.
\end{abstract}

\section{INTRODUCTION}

Fluor-Daniel Incorporated (FDI) is the primary site contractor for the environmental remediation management contract (ERMC) at Fernald, Ohio. As part of the environmental remediation effort, FDI has expressed an interest in recovering hydrogen fluoride (HF) for industrial use from calcium fluoride $\left(\mathrm{CaF}_{2}\right)$ and magnesium fluoride $\left(\mathrm{MgF}_{2}\right)$ uranium reduction slags. These slag inventories are present at Fernald and other uranium metal production sites. Currently, hydrogen fluoride is produced industrially by a two-stage reaction of fluorspar (calcium fluoride) with sulfuric acid $\left(\mathrm{H}_{2} \mathrm{SO}_{4}\right)$. 1,2 However, the recovery of $\mathrm{HF}$ from $\mathrm{MgF}_{2}$ has not been demonstrated on an industrial scale. In an effort to facilitate laboratory scale and pilot plant scale studies of these reactions, Los Alamos National Laboratory (LANL) is modeling the thermodynamics of the processes under a number of experimental conditions. A brief description of the modeling approach is presented in the following paragraph. The results are discussed in the subsequent text.

In this work, computer modeling has been used to predict the equilibrium composition and product yield as a function of temperature for the reactions of interest. Los Alamos National Laboratory currently possesses very extensive and sophisticated capabilities in thermodynamic computer modeling. This modeling technique has been previously used in the evaluation of proposed variations in chemical processing conditions, such as changes in reactant compositions, system pressure, etc., in support of diverse chemical processing operations. The model 
has been verified in several experimental works.3,4,5 The model involves rigorous computer calculations to generate predicted equilibrium compositions and phase assemblages for complex, heterogeneous chemical systems. The modeling operation is based on the thermodynamic principle that equilibrium (final) compositions correspond to the global free energy minimum for the specified chemical system. This involves the solution of large matrices of Gibbs energy expressions and requires substantial computer processing time. The models are designed to utilize advanced, computer-based numerical techniques.

\section{PRELIMINARY RESULTS OF COMPUTER MODELING}

Computer modeling was conducted separately on the $\mathrm{MgF}_{2}$ and $\mathrm{CaF}_{2}$ reactions with $\mathrm{H}_{2} \mathrm{SO}_{4}$ for the production of $\mathrm{HF}$. The speciation as a function of temperature and reaction atmosphere (initial gas phase composition) were conducted. Initial results are presented herein.

\section{A. Computer Modeling of $\mathrm{HF}$ Generation via the $\mathrm{CaF}_{2}-\mathrm{H}_{2} \mathrm{SO}_{4}$ Reaction in Air}

As mentioned above, the production of $\mathrm{HF}$ from the reaction between $\mathrm{CaF}_{2}$ and $\mathrm{H}_{2} \mathrm{SO}_{4}$ involves two stages. The temperature range over which the modeling was conducted bracketed the operating temperatures of both the 'Ko-Kneader' (reactor) and rotary kiln unit processes. The optimum temperature for HF formation is revealed in the modeling results (see Fig. 1). Note that an optimum temperature near $400^{\circ} \mathrm{F}$ was predicted by the computer model. This is close to the rotary kiln temperature used for the second stage of $\mathrm{CaF}_{2}$ processing. ${ }^{2}$ It is important to note that the optimum range is broad; only small variations in composition occur on either side of the optimum temperature (observe ordinate in Fig. 1). The optimum temperature can be more closely defined in further modeling efforts.

The model generated a set of predicted system compositions at each temperature ( 5 values) surveyed in the study. This involved the simultaneous solution of $81 \mathrm{Gibbs}$ energy expressions for the formation of all possible substances in the chemical system. The results are reflected in the construction of the plot in Fig. 1. Further details are available upon request. 


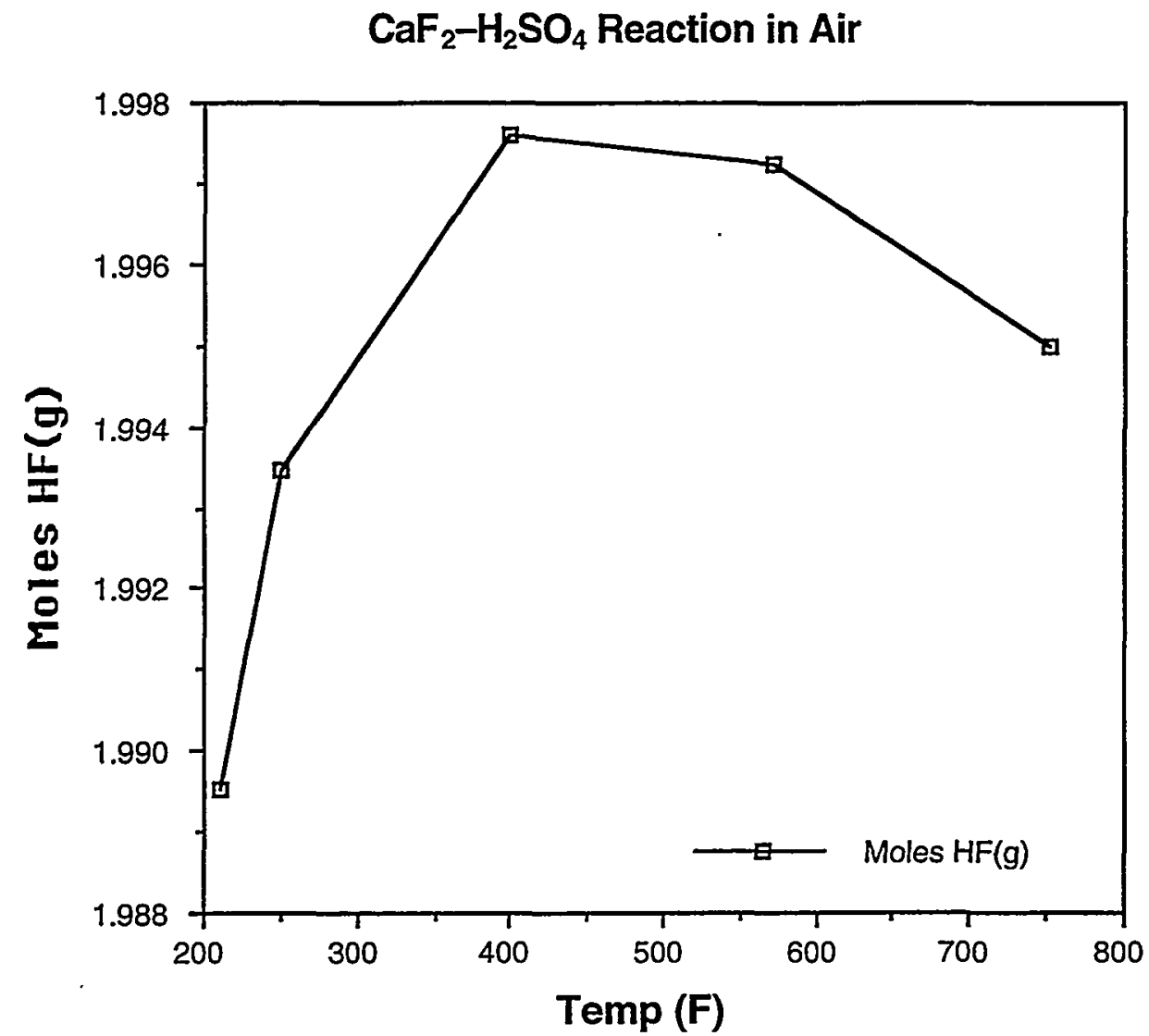

Fig. 1. $\mathrm{HF}$ generation as a function of reaction temperature for $\mathrm{CaF}_{2}$ processing.

\section{B. Computer Modeling of $\mathrm{HF}$ Generation via the $\mathrm{MgF}_{2}-\mathrm{H}_{2} \mathrm{SO}_{4}$ Reaction in Air}

The temperature range over which the modeling was conducted bracketed the operating temperatures (7 values) of both the 'Ko-Kneader' and rotary kiln as used in the $\mathrm{CaF}_{2}$ processing operation. (Note: this temperature selection was based on information presented in the literature.2,6 As previously mentioned, no industrial scale demonstration has been conducted with $\mathrm{MgF}_{2}$ directly.) The production of $\mathrm{HF}$ as a function of temperature is displayed in Fig. 2. Note that the mole numbers of $\mathrm{MgF}_{2}$ are coplotted along with those of $\mathrm{MgSO}_{4}$, an ancillary reaction product. An optimum processing temperature of $\sim 660^{\circ} \mathrm{F}$ has been predicted for the generation of $\mathrm{HF}$ from $\mathrm{MgF}_{2}$.

It is important to note that this optimum temperature does not coincide with the maximum depletion of $\mathrm{MgF}_{2}$. In addition, the interactive dependence between $\mathrm{HF}$ formation and appearance of $\mathrm{MgSO}_{4}$ has been revealed. The character of this interaction is not obvious. It involves complex chemistry and the variance of mole numbers for a suite of other ancillary species. (Note: the formation reactions for 91 substances were considered in this model.) Further details are available upon request.

Previous thermogravimetric studies were conducted to characterize the extent of $\mathrm{MgF}_{2}-\mathrm{H}_{2} \mathrm{SO}_{4}$ reactions as a function of temperature. Based upon results of 
those studies ${ }^{6}$, the evolution of HF from $\mathrm{MgF}_{2}$ (27-mg scale) is complete by about $275^{\circ} \mathrm{C}$.

\section{$\mathrm{MgF}_{2}-\mathrm{H}_{2} \mathrm{SO}_{4}$ Reaction in Air}

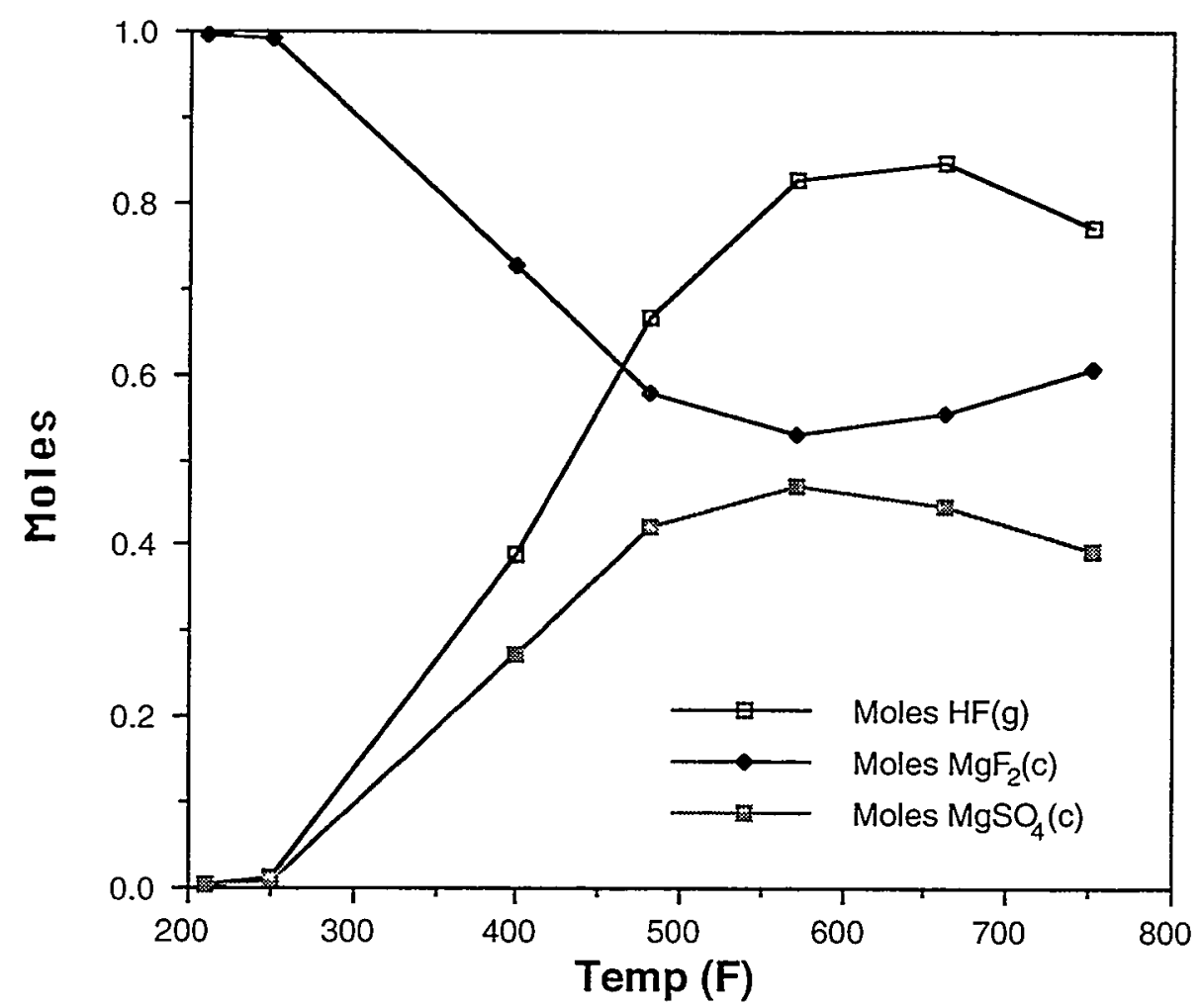

Fig. 2. Partial compositional profile for $\mathrm{MgF}_{2}$ reaction with $\mathrm{H}_{2} \mathrm{SO}_{4}$ and concurrent $\mathrm{HF}$ formation.

The present modeling effort predicted that the most efficient conversions are achieved at temperatures around $350^{\circ} \mathrm{C}$ or $662^{\circ} \mathrm{F}$ (see Fig. 2). Modeling smaller temperature increments around $662^{\circ} \mathrm{F}$ would specify the predicted optimum more closely.

The decomposition of unreacted $\mathrm{H}_{2} \mathrm{SO}_{4}$ to water vapor and sulphur trioxide gas $\left(\mathrm{SO}_{3(\mathrm{~g})}\right)$ is reflected in changes to the system composition. Fig. 3 shows the increase in mole numbers for water vapor and $\mathrm{SO}_{3}$. At the highest temperature studied, the moles of water and $\mathrm{SO}_{3}$ are almost identical in magnitude. These features are shown coplotted with HF content.

The predicted formation of $\mathrm{FSO}_{3} \mathrm{H}_{(\mathrm{g})}$ (fluosulfonic acid or fluorosulfuric acid) is optimum at approximately $500^{\circ} \mathrm{F}$ (see Fig. 4). Fig. 4 also indicates that above this temperature, $\mathrm{FSO}_{3} \mathrm{H}$ decomposes. The decomposition of $\mathrm{FSO}_{3} \mathrm{H}$ explains the separation between the optimum temperature for $\mathrm{HF}$ formation and the minimum $\mathrm{MgF}_{2}$ composition. The effects of $\mathrm{H}_{2} \mathrm{SO}_{4}$ purity were previously reported. ${ }^{1}$ According to the results of that work, use of $\mathrm{H}_{2} \mathrm{SO}_{4}$ of greater than 
$99 \%$ purity was not advised. The $\mathrm{SO}_{3(g)}$ evolves from the $\mathrm{H}_{2} \mathrm{SO}_{4}$ decomposition and forms $\mathrm{FSO}_{3} \mathrm{H}$ in a gas phase reaction with $\mathrm{HF}$. For the $\mathrm{MgF}_{2}-\mathrm{H}_{2} \mathrm{SO}_{4}$ reaction, operational temperatures should be selected to obviate the formation of $\mathrm{FSO}_{3} \mathrm{H}$.

Traditionally, these processing schemes are conducted in air. We investigated the effects of a nitrogen atmosphere over the chemical system. The model revealed that the speciation and optimum yield temperatures were not significantly affected when the atmosphere was changed from air to $\mathrm{N}_{2}$.

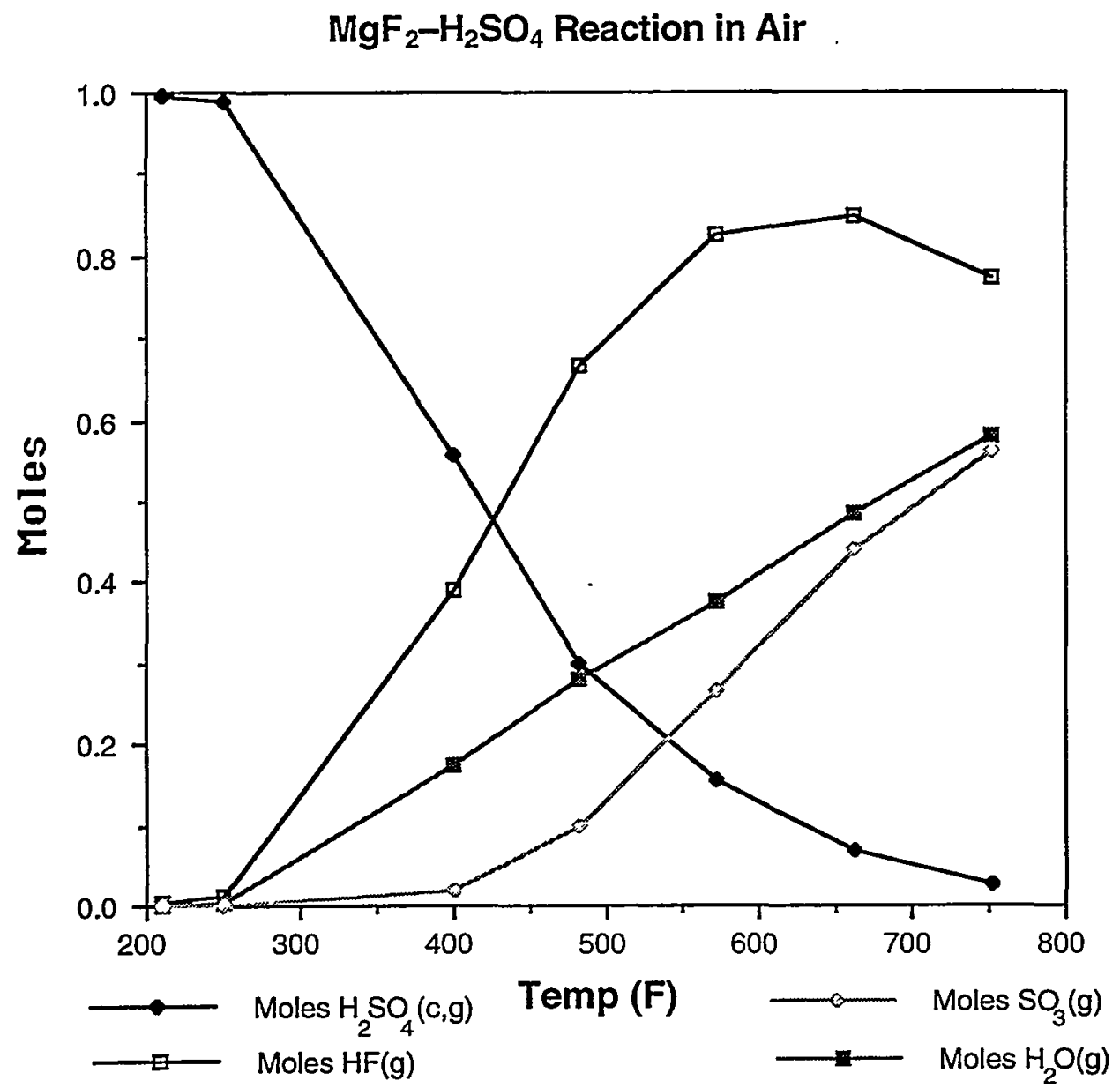

Fig. 3. Effect of $\mathrm{H}_{2} \mathrm{SO}_{4}$ composition on the appearance of selected species. 


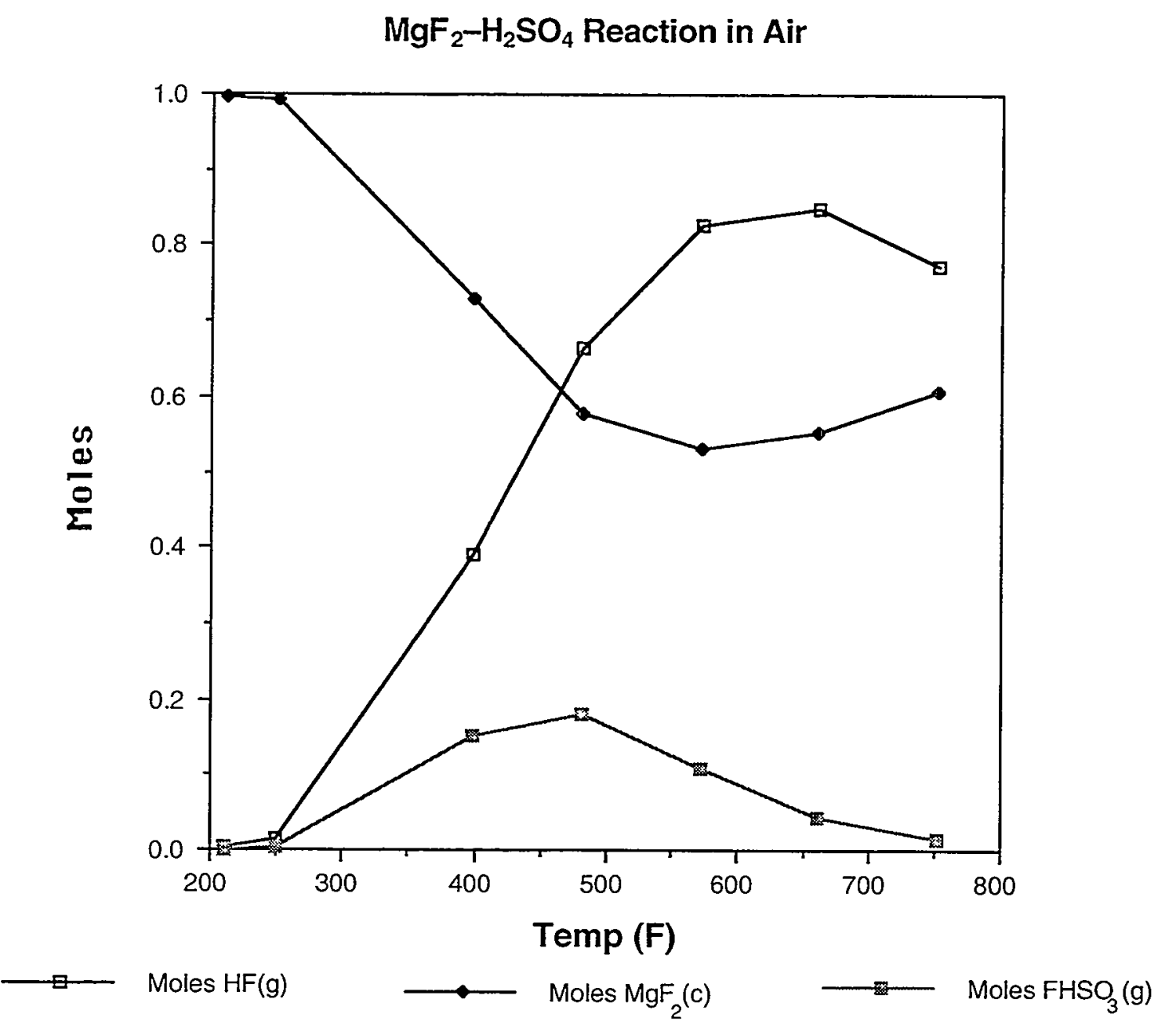

Fig. 4. Plot showing the relationship between $\mathrm{MgF}_{2}, \mathrm{HF}$ and $\mathrm{FHSO}_{3}$ mole numbers as a function of temperature. 


\section{REFERENCES}

1. W. R. Rogers and K. Muller, Chemical Engineering Progress 59 (5), 85 (1963).

2. N. P. Chopey, Chemical Engineering 94 (April 30, 1962).

3. K. M. Axler et al., J. Nuc. Mat. 187, 183-185 (1992).

4. K. M. Axler et al., National Physical Laboratory Report DMM(D)123, Teddington, UK (1991).

5. K. M. Axler et al., Los Alamos National Laboratory Report LA-12458-MS (April, 1994).

6. N. P. Kurin, N.S. Turaev, V.P. Pischchulin, and F.I. Tischenko, Izv. Tomsk. Politekhn. In-ta.(250), 30-1 (Bulletin of the Tomsk Polytechnic Institute, 1975). 